\title{
New trends and patients ' demand in the field of dentistry, the challenges
}

\author{
Aras Rauf \\ University of Sulaimani, Iraq
}

Correspondence: Aras Rauf,The Dean of College of Dentistry, University of Sulaimani, Sulaimaniyah, Kurdistan Region, Iraq, Tel 009647702419930, Email aras.rauf@univsul.edu.iq

Received: February 27, 2018 | Published: April 26, 2018

Copyright@ 2018 Rauf. This is an open access article distributed under the terms of the Creative Commons Attribution License, which permits unrestricted use, distribution, and reproduction in any medium, provided the original author and source are credited.

\section{Editorial}

It's my fabulous gratification and responsibility to be delegated by Journal of Dental Science, Oral and Maxillofacial Research to write this letter.

In the past few decades, technological development happened very fast as a revolution which made a major change in our life. The dental profession and dental technology had a biggest share from this advancement; one can say that it was the most valuable event in the field of dentistry to improve the quality of oral health. Furthermore, rapid expansion of prototyping in all directions, particularly in producing human anatomically accurate parts, have raised the question of how to employ this technology in field of cosmetic dentistry, dental implants and soft tissue facial implants by rapid and anatomically accurate fabrication using the principles of CAD/CAM.

Advances in implant dentistry and the following keywords denote hot topics in this field beside CBCT radiography, template-guided implant placement, minimally invasive techniques, short lengths and reduced implant diameters, novel bone grafting techniques, $\mathrm{CAD} / \mathrm{CAM}$ prosthetics, optical intraoral impressions, and other uncountable advanced technologies.
Dentistry and dental career then started to follow a new lane deviated greatly from that before twenty or thirty years. Improvements happened in people's attitude, life style plus the standard of living; people started living with health and well being particularly in developed countries, of course, their demands started to change as well. Even dental student and their parents started looking through a different vista to the future of dentistry and having a greater vision about their career.

However, I started feeling a bit alert and worry that dental profession started to become more literate or materialistic than being a humanitarian profession. Dentists started taking care of a limited aspect of this great profession. In the midst of this conflict, important aspects are going to be ignored or missed.

We hope that there will be an assortment of interest and care to all aspects of dentistry, in order to give enough space to each aspect to grow. 